\title{
Challenging the concept of bacteria subsisting on antibiotics
}

\author{
Fiona Walsh ${ }^{\mathrm{a}, *}$, Sebastian G.B. Amyes ${ }^{\mathrm{b}}$, Brion Duffy ${ }^{\mathrm{a}}$ \\ a Bacteriology, Agroscope-Research Station Changins-Wädenswil ACW, Federal Department of Economic Affairs, Education and Research (EAER), \\ Wädenswil, Switzerland \\ ${ }^{\mathrm{b}}$ Molecular Chemotherapy, Medical Microbiology, Medical School, University of Edinburgh, Edinburgh, UK
}

\section{A R T I C L E I N F O}

\section{Article history:}

Received 28 January 2013

Accepted 28 January 2013

\section{Keywords:}

Catabolism

Antibiotic

Subsistence

$\beta$-Lactam

Streptomycin

Trimethoprim

\begin{abstract}
A B S T R A C T
Antibiotic resistance concerns have been compounded by a report that soil bacteria can catabolise antibiotics, i.e. break down and use them as a sole carbon source. To date this has not been verified or reproduced, therefore in this study soil bacteria were screened to verify and reproduce this hypothesis. Survival in high concentrations of antibiotics was initially observed; however, on further analysis these bacteria either did not degrade the antibiotics or they used an intrinsic resistance mechanism ( $\beta$ lactamases) to degrade the $\beta$-lactams, as demonstrated by high-performance liquid chromatography. These results did not verify or reproduce the hypothesis that bacteria subsist on antibiotics or catabolise antibiotics as previously reported. This study identified that bacteria with a catabolising phenotype did not degrade streptomycin or trimethoprim and therefore could not utilise the antibiotics as a nutrient source. Therefore, we conclude that soil bacteria do not catabolise antibiotics.
\end{abstract}

(c) 2013 Elsevier B.V. and the International Society of Chemotherapy. All rights reserved.

\section{Introduction}

Antibiotic resistance is emerging as one of the greatest challenges to human health [1]. Within the past 20 years, antibiotic resistance has developed from resistance to single classes of antibiotics to multidrug resistance (MDR) and extensive drug resistance (XDR) [2]. Catabolism, i.e. the capacity of bacteria to not only resist but to subsist on antibiotics, has been presented as a potentially crucial step in the evolution of antibiotic resistance from MDR and XDR to untreatable infections. In 2008, a novel hypothesis was introduced, namely antibiotic catabolism, defined by the identification of soil bacteria from different phyla that were capable of degrading and utilising different classes of antibiotics as a sole carbon source [3]. Bacterial catabolism of antibiotics is a concept that surpasses antibiotic resistance and MDR in terms of complexity in treating and managing bacterial infections. Therefore, it is important for the future successful management of antibiotic-treated bacterial infections that we are able to distinguish between conventional resistance mechanisms and the ability of bacteria to subsist on antibiotics.

Research on antibiotic degradation was reported in the 1970s, but the novel study on multiple antibiotic classes catabolised by soil bacteria exposed the full extent and distribution of antibioticdegrading genes in the environment [4]. This study has specifically

\footnotetext{
* Corresponding author. Tel.: +41 447836329.

E-mail addresses: fiona.walsh@agroscope.admin.ch, fiona1walsh@gmail.com (F. Walsh).
}

led to the scientific belief that soil bacteria contain previously uncharacterised antibiotic-degrading resistance enzymes and that soil bacteria can subsist on antibiotics, with respect to at least 18 different antibiotics [3]. The only resistance-degrading mechanism described prior to this study was the degradation of $\beta$-lactam antibiotics by the $\beta$-lactamase resistance mechanisms. The characterised mechanisms of resistance to all other classes of antibiotics do not include degradation. This study revolutionised the current thinking on how bacteria can resist antibiotics whilst also identifying soil bacteria as a potentially large reservoir of novel resistance mechanisms. Antibiotic catabolism would protect the entire bacterial community from the inhibitory effects of antibiotics and concurrently increase the population size as they use the antibiotics as a nutrient source.

Although the hypothesis of antibiotic catabolism by soil bacteria was published 5 years ago, this hypothesis has neither been reproduced nor verified. The aims of the current study were therefore to verify the hypothesis of soil bacteria subsisting on antibiotics.

\section{Materials and methods}

\subsection{Sampling and site descriptions}

The soil sampling sites, locations and elevations are described in Table 1 . Soil $\mathrm{pH}$ was determined by suspending $1 \mathrm{~g}$ of soil in $2.5 \mathrm{~mL}$ of $0.01 \mathrm{M} \mathrm{CaCl}_{2}$ and measuring the $\mathrm{pH}$ using a glass electrode [5]. The $\mathrm{pH}$ of each soil was determined three times and the mean \pm standard deviation is given in Table 1. 
Table 1

Geographic and descriptive characteristics of the analysed urban, agricultural and pristine soil samples.

\begin{tabular}{|c|c|c|c|c|c|c|}
\hline Sample ID & Description & Environmental matter & Elevation $(\mathrm{m})$ & Latitude & Longitude & $\mathrm{pH}(n=3)$ \\
\hline FWS1 & Wädenswil Apple Orchard & Orchard soil & 407 & 47.2333 & 8.6667 & $7.0 \pm 0.1$ \\
\hline FWS2 & Benedictine Abbey & Farm soil & 880 & 47.1167 & 8.75 & $7.1 \pm 0.1$ \\
\hline FWS3 & Hospital garden & Lawn soil & 667 & 46.7167 & 9.4333 & $7.3 \pm 0$ \\
\hline FWS4 & Lindau Apple Orchard & Orchard soil & 485 & 47.4833 & 8.2 & $4.1 \pm 0.2$ \\
\hline FWS5 & Güttingen Apple Orchard & Orchard soil & 503 & 47.6 & 9.2833 & $5.3 \pm 0.1$ \\
\hline FWS6 & Rütli meadow & Meadow soil & 835 & 46.9667 & 8.6 & $7.1 \pm 0.2$ \\
\hline FWS7 & Area beside Lake Zürich & Lawn soil & 408 & 47.3667 & 8.55 & $7.0 \pm 0.1$ \\
\hline FWS8 & Matterhorn mountain trail & Alpine soil & 1936 & 46.0167 & 7.75 & $7.2 \pm 0.1$ \\
\hline FWS9 & Farmland treated with pig manure & Manured soil & 592 & 47.1833 & 8.3167 & $5.7 \pm 0.2$ \\
\hline FWS10 & Mountain near Zürich & Mountain forest soil & 700 & 47.3496 & 8.492 & $7.0 \pm 0$ \\
\hline
\end{tabular}

\subsection{Sampling strategy}

For each sample site, eight soil core samples were combined. Soil samples consisted of eight soil cores $(10 \mathrm{~cm}$ depth) per replicate taken using a stainless steel corer with an internal diameter of $2.5 \mathrm{~cm}$. Soil cores were pooled for each replicate in the field. Pooling of soil cores is standardly applied in order to obtain more representative samples for a certain field plot or a specific experimental treatment [6-8].

\subsection{Isolation of antibiotic-catabolising bacteria from Swiss soil}

Soil bacteria with an antibiotic-catabolising phenotype were isolated and cultured using methods described previously from ten soils under a variety of anthropogenic influences from urban, pristine and farmland soils (Table 1) [3]. Minimal medium [single carbon source (SCS)] broth cultures of putative catabolising bacteria were serially diluted and spread-plated onto SCS agar supplemented with the appropriate corresponding antibiotic [3]. Negative controls comprised SCS agar without antibiotic, inoculated in the same manner as described by Dantas et al. [3]. The antibiotics tested comprised penicillin, dicloxacillin, amikacin, cefalexin, kanamycin, gentamicin, sisomicin, streptomycin, vancomycin, levofloxacin, ciprofloxacin, sulfamethizole, nalidixic acid, chloramphenicol, dcycloserine, cefotaxime, novobiocin, trimethoprim, sulfisoxazole, tetracycline, erythromycin, colistin and rifampicin. All antibiotics and chemicals, except kanamycin and vancomycin (Carl Roth GmbH and Co. KG, Karlsruhe, Germany), were obtained from SigmaAldrich Chemie GmbH (Buchs, Switzerland).

Two bacteria described as having the capacity to catabolise carbenicillin and penicillin were obtained from the Dantas group: CA-S3F-1, Burkholderia sp.; and PE-S2R-1, Burkholderia sp. Due to unforeseen circumstances in the Dantas laboratory, further isolates catabolising non- $\beta$-lactam antibiotics could not be provided.

The abilities of the antibiotic-catabolising bacteria to grow or survive in sterile-filtered SCS medium without added antibiotics were investigated. Assimilable organic carbon-free glassware was prepared as previously described [9]. Bacteria were inoculated into SCS medium and grown at $22^{\circ} \mathrm{C}$ for 3 days. Then, $10 \mu \mathrm{L}$ was removed and added to SCS medium with and without antibiotic at a final concentration of $1 \mathrm{~g} / \mathrm{L}$. Total bacterial counts were performed on Days $0,5,7,14,21$ and 28 by plate counts on Luria-Bertani (LB) agar. The total organic carbon and dissolved organic carbon (DOC) concentrations were determined as previously described [10].

\subsection{Resistance profiling of antibiotic-catabolising bacteria}

The resistance profile of each isolate was determined as previously described using $1 \mathrm{mg} / \mathrm{mL}$ of each antibiotic [11]. Antibiotic susceptibility tests were performed in duplicate. Where there was a discrepancy between the two results, susceptibility testing was performed a third time [12,13]. Two consistent susceptibility results were taken as the final result.

\subsection{Bacterial phylogenetic profiling}

The phylogenetic profiles of the bacteria were determined as previously described [3]. Briefly, the variable regions (nucleotides 63-1389) of the 16S rRNA genes were amplified by PCR and sequenced. The phylogeny of the bacteria based on sequence variation of the 16S rRNA genes was identified using BLASTn and the Greengenes 2011 database. A phylogenetic tree of the bacterial species based on the 16S rRNA sequences was constructed using the neighbour-joining algorithm in ARB [14].

\subsection{High-performance liquid chromatography (HPLC) investigation of bacterial antibiotic degradation}

Degradation of carbenicillin (bacteria CA-S3F-1, Burkholderia sp.), penicillin (bacteria PE-C-1, Pseudomonas sp. and bacteria PE-S2R-1, Burkholderia sp.), streptomycin (bacteria ST-C-1, Achromobacter sp.) and trimethoprim (bacteria TR-C-1, Pseudomonas sp.) was investigated by HPLC [1] performed using a Dionex PDA-100 photodiode array detector, Chromeleon v.6.80 software (Dionex, Idstein, Germany) and the conditions described in Table 2. Aliquots $(80 \mu \mathrm{L})$ of cultures grown in SCS medium containing $1 \mathrm{mg} / \mathrm{mL}$ of antibiotic were inoculated into $20 \mathrm{~mL}$ of SCS medium containing $1 \mathrm{mg} / \mathrm{mL}$ of appropriate antibiotic and incubated at $22^{\circ} \mathrm{C}$ for 28 days. SCS-antibiotic medium containing no bacteria was also incubated at $22^{\circ} \mathrm{C}$. Then, $1 \mathrm{~mL}$ was removed at Days $0,2,4,7,14,21$ and 28 and was analysed in duplicate using HPLC. Following the initial results of the HPLC experiments, all bacterial isolates were also inoculated into SCS medium containing no antibiotic as negative controls at a final concentration of $10^{3}$ or $10^{4} \mathrm{CFU} / \mathrm{mL}$ and incubated at $22^{\circ} \mathrm{C}$ for 28 days.

\subsection{Biological activity of the antibiotic solutions following incubation with the catabolising bacteria}

The biological activities of the trimethoprim and streptomycin HPLC solutions containing the respective catabolising bacteria from Days 0,14 and 28 were investigated using an adaptation of the antibiotic disk diffusion assay [15]. Staphylococcus aureus ATCC

Table 2

Description of the high-performance liquid chromatography (HPLC) experimental conditions and columns.

\begin{tabular}{llll}
\hline Antibiotic & $\begin{array}{l}\text { Wavelength } \\
(\mathrm{nm})\end{array}$ & $\begin{array}{l}\text { Flow rate } \\
(\mathrm{mL} / \mathrm{min})\end{array}$ & Column \\
\hline Penicillin & 220 & 0.7 & Nucleosil 100-5, C18 \\
Carbenicillin & 220 & 0.7 & Nucleosil 100-5, C18 \\
Streptomycin & 195 & 0.7 & Nucleosil 100-5, C18 \\
Trimethoprim & 250 & 0.7 & Nucleosil 100-5, C18 \\
\hline
\end{tabular}




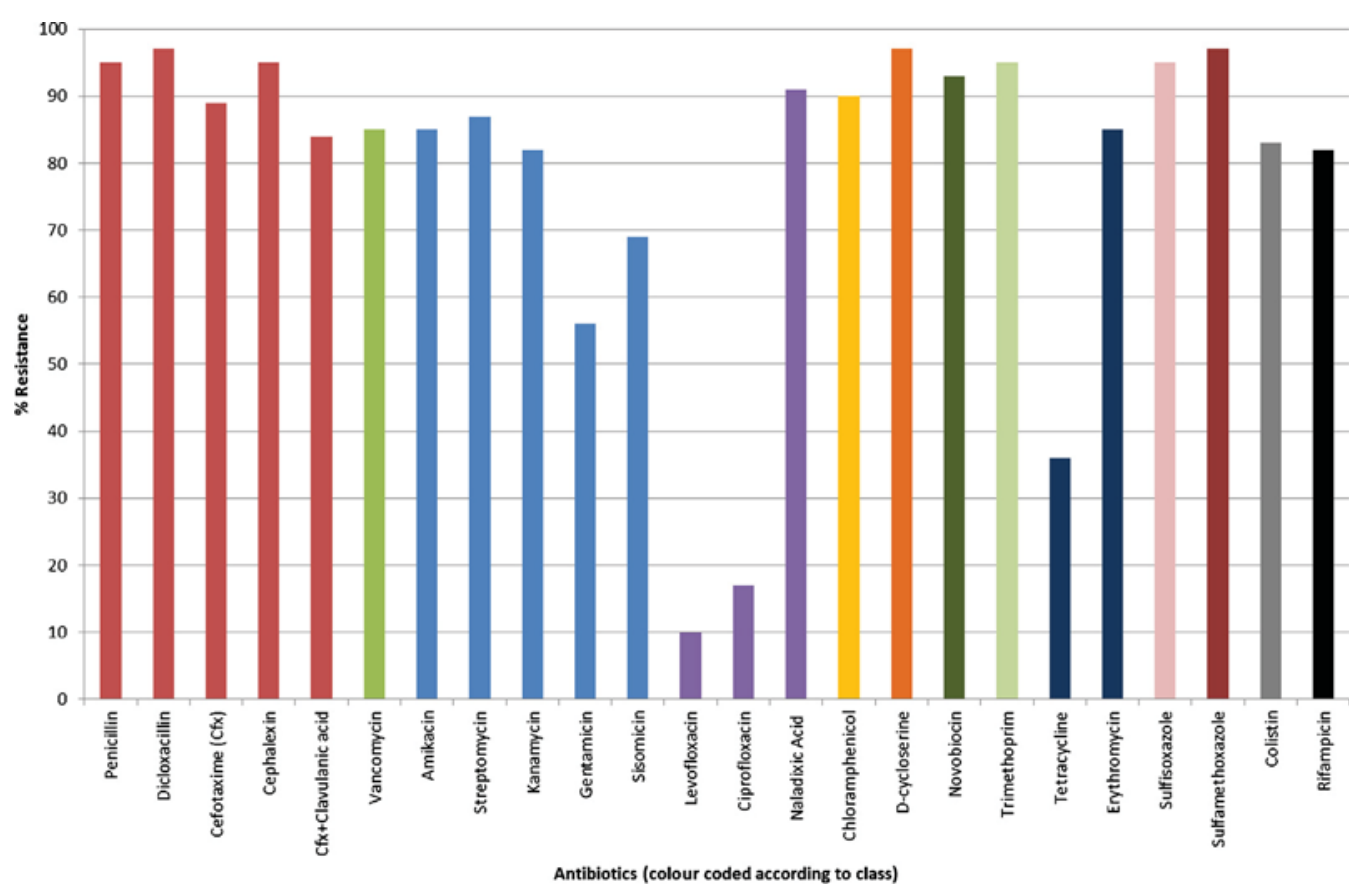

Fig. 1. Antibiotic resistance profiles of 140 isolates from ten soils, showing percentage of isolates resistant to antibiotics at a concentration of $1 \mathrm{mg} / \mathrm{mL}$.

25923 ( 0.5 McFarland) was spread on LB agar plates. The HPLC solutions (Days 0,14 and 28) were sterile-filtered and $15 \mu \mathrm{L}$ was added to a sterile filter paper disk on the $S$. aureus agar plates. The plates were incubated at $37^{\circ} \mathrm{C}$ and the zone diameters of the disk diffusion assays were measured after $16 \mathrm{~h}$.

\subsection{Extraction of $\beta$-lactamase enzymes and HPLC investigation of $\beta$-lactam degradation by the $\beta$-lactamase enzymes}

Cultures of CA-S3F-1, PE-C-1 and PE-S2R-1 grown in the respective antibiotic $(1 \mathrm{mg} / \mathrm{mL})$-containing LB broth at $26^{\circ} \mathrm{C}$ with shaking overnight were diluted 1 in 10 in antibiotic $(1 \mathrm{mg} / \mathrm{mL})$-containing LB broth and incubated for a further $4 \mathrm{~h}$. The filtered $(0.2 \mu \mathrm{m}$ filters), washed supernatants were used in the crude $\beta$-lactamase enzyme assays using nitrocefin at $100 \mu \mathrm{M}$ at a wavelength of $486 \mathrm{~nm}$ [16]. Escherichia coli transformed with pUC19 plasmid (AmpC $\beta$ lactamase-producing) was used as a positive control. Degradation of carbenicillin and penicillin was investigated using HPLC in the same manner as the HPLC antibiotic degradation experiments.

\section{Results}

Bacteria presenting a catabolism phenotype (growth in SCS medium containing $1 \mathrm{mg} / \mathrm{mL}$ of antibiotic) were isolated from all ten soil sources consisting of farmland, pristine soil and urban environments (Table 1). The antibiotics on which the bacteria presented a catabolism phenotype comprised penicillin, dicloxacillin, amikacin, kanamycin, gentamicin, sisomicin, streptomycin, cefalexin, vancomycin, trimethoprim, cefotaxime, sulfamethizole and erythromycin, representing many different classes of antibiotics, including natural, semisynthetic and synthetic. All ten soils contained bacteria presenting a catabolism phenotype both to the $\beta$-lactam antibiotic penicillin and the macrolide erythromycin. In total, 140 bacteria with an antibioticcatabolising phenotype were identified.

Antibiotic resistance profiling of the isolated bacteria identified that $>80 \%$ were capable of growth at $1 \mathrm{mg} / \mathrm{mL}$ of almost all antibiotics (Fig. 1). The pattern and distribution of high-level resistance did not in all cases correspond to the levels of catabolism against that antibiotic. However, for the fluoroquinolones and tetracycline, which had low levels of resistance, no catabolising isolates were identified. 16S rRNA genetic phylotyping identified that the majority of bacteria were Pseudomonadales $(n=67)$ followed by Burkholderiales ( $n=22$ ) (Fig. 2), which were similar to the phylotypes previously identified [3]. The Actinomycetales were the only Gram-positive bacteria identified. All bacterial isolates were capable of growth in SCS medium without antibiotic, as this medium was not carbon-free as described by Dantas et al. but contained $15 \mathrm{mg}$ of ethylene diamine tetra-acetic acid (EDTA) per litre of SCS medium [3]. DOC tests identified a DOC concentration of $8.53 \mathrm{mg} / \mathrm{L}$ in the SCS medium [9]. Thus, the medium contained sufficient carbon without antibiotics to support bacterial growth. This constituent was overlooked by the seminal study [3]. Growth of selected strains of bacteria in SCS medium without antibiotics increased by a minimum of $2 \log$ growth over 28 days (Fig. 3 ).

The HPLC experiments were performed to investigate whether the antibiotics streptomycin (bacteria ST-C-1, Achromobacter sp.), trimethoprim (bacteria TR-C-1, Pseudomonas sp.), penicillin (bacteria PE-C-1, Pseudomonas sp. and PE-S2R-1, Burkholderia sp.) and carbenicillin (bacteria CA-S3F-1, Burkholderia sp.) were degraded in the presence of the catabolising bacteria (Fig. 4a). The bacteria used in the penicillin and carbenicillin HPLC experiments included isolates (bacteria PE-S2R-1 and bacteria CA-S3F-1) previously reported as antibiotic catabolisers [3]. Three different classes of antibiotic, which have different target sites and resistance mechanisms, were chosen. Streptomycin is a protein synthesis pathway inhibitor, trimethoprim is a dihydrofolate synthesis pathway inhibitor, and the $\beta$-lactams carbenicillin and penicillin are cell wall synthesis inhibitors. There were no statistically significant differences between the concentrations of streptomycin and trimethoprim antibiotics with and without the bacteria, as determined by Student's $t$-test. Bacteria were viable after 28 days incubation as tested by growth on LB agar. These results indicated that streptomycin and trimethoprim were not degraded over 28 days and the bacteria were still viable at Day 28 . These antibiotics were not catabolised even though the bacteria presented with the same phenotype as previously described antibiotic catabolisers. The biological activities of streptomycin and trimethoprim at 


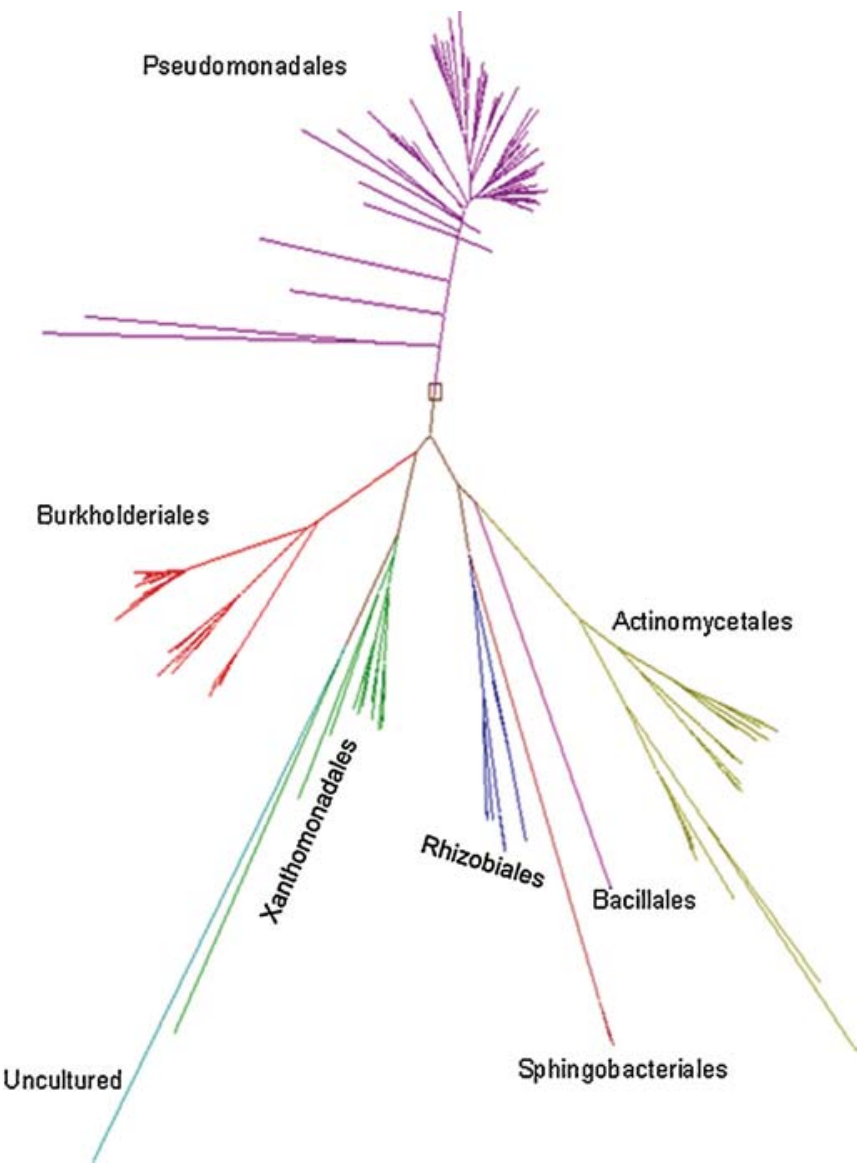

Fig. 2. Phylogenetic distribution of 140 bacterial isolates from ten soils.
Day 28 were investigated using antibiotic disk diffusion assays. The diameters of the zones of inhibition did not decrease for streptomycin or trimethoprim solutions between 0 and 28 days. Streptomycin and trimethoprim were as biologically active at Day 28 as at Day 0, confirming that they did not lose their biological activities as would be expected if they were degraded.

The $\beta$-lactam antibiotics penicillin and carbenicillin degraded in the presence and absence of the bacteria. Penicillin and the $\beta$-lactam antibiotics are not stable and degrade easily, which is why penicillin was so difficult to produce in large quantities initially after its discovery. The rate and extent of degradation were higher when the bacteria were present than in the medium lacking bacteria (Fig. $4 a$ ). The $\beta$-lactam antibiotics are the only class of antibiotics known to be degraded due to a resistance mechanism, namely the $\beta$-lactamases. Pseudomonas and Burkholderia spp. both contain chromosomally mediated AmpC enzymes capable of degrading $\beta$-lactam antibiotics $[17,18]$.

The $\beta$-lactam-degrading bacteria (PE-C-1, PE-S2R-1 and CAS3F-1) were investigated for the production of $\beta$-lactam-degrading $\beta$-lactamases. Production of $\beta$-lactamases was confirmed by digestion of nitrocefin as detected by ultraviolet spectrophotometry over time. The rate of $\beta$-lactam degradation was determined by plotting the absorbance against time for each bacteria. Using these plots, the slopes of the lines for CA-S3F-1 (carbenicillin), PE-S2R-1 (penicillin) and PE-C- 1 (penicillin) were $0.0642 x+0.1202,0.0097 x+0.0977$ and $0.0041 x+0.1278$, respectively, indicating that degradation of the $\beta$-lactam ring was fastest by the $\beta$-lactamase extracted from CAS3F-1, followed by PE-S2R-1 and then PE-C-1. Therefore, each bacteria contained $\beta$-lactamases capable of degrading the $\beta$-lactam ring of the $\beta$-lactam antibiotics. The concentration of protein in the assays was the same and thus the differences in rates of degradation were not due to variations in protein (enzyme) concentrations.

Degradation of carbenicillin and penicillin by the extracted $\beta$-lactamases was further investigated by HPLC (Fig. 4b). These results identified that the $\beta$-lactamases extracted from PE-S2R-1 (described in a previous study as a $\beta$-lactam cataboliser) digested

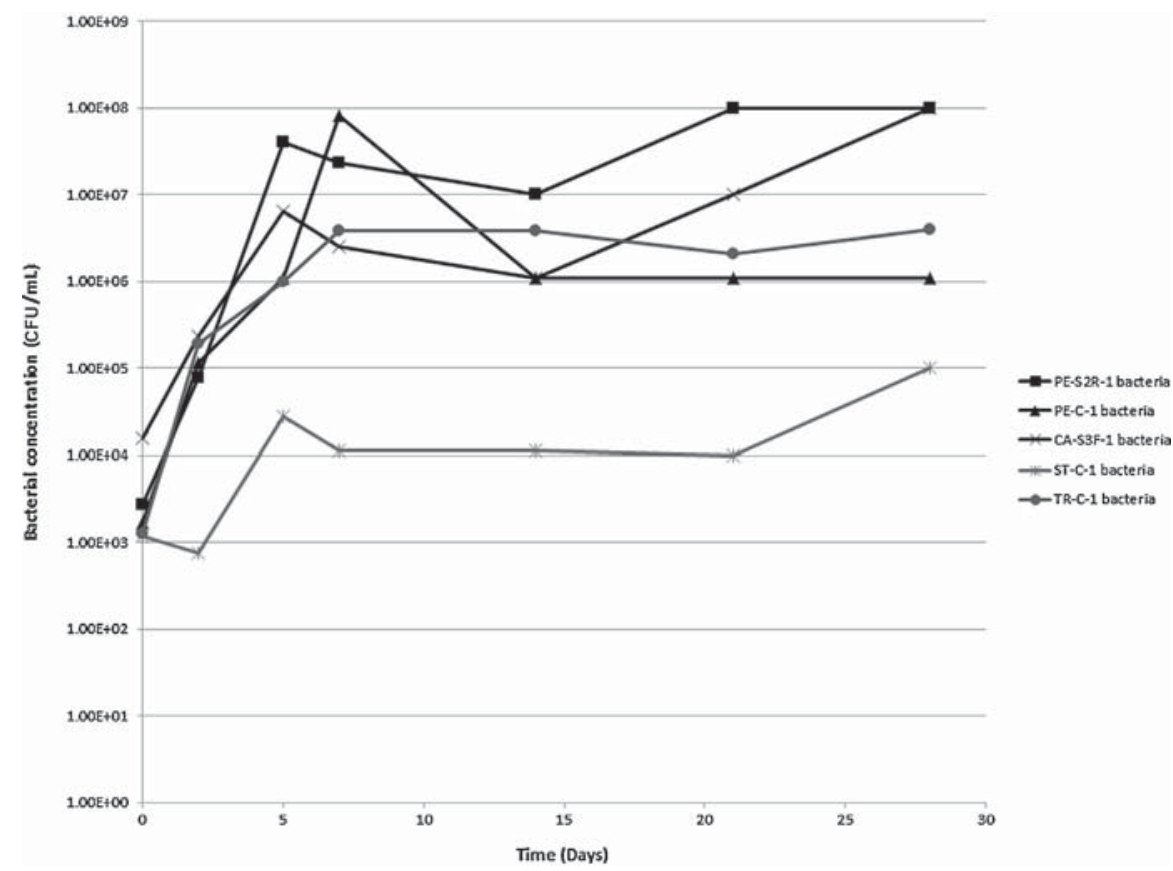

Fig. 3. Growth of the five bacteria presenting catabolism phenotypes in single carbon source (SCS) medium without antibiotic over 28 days. The five bacteria are those used in the high-performance liquid chromatography (HPLC) experiments: PE-S2R-1, Burkholderia sp.; PE-C-1, Pseudomonas sp.; CA-S3F-1, Burkholderia sp.; ST-C-1, Achromobacter sp.; TR-C-1, Pseudomonas sp. 

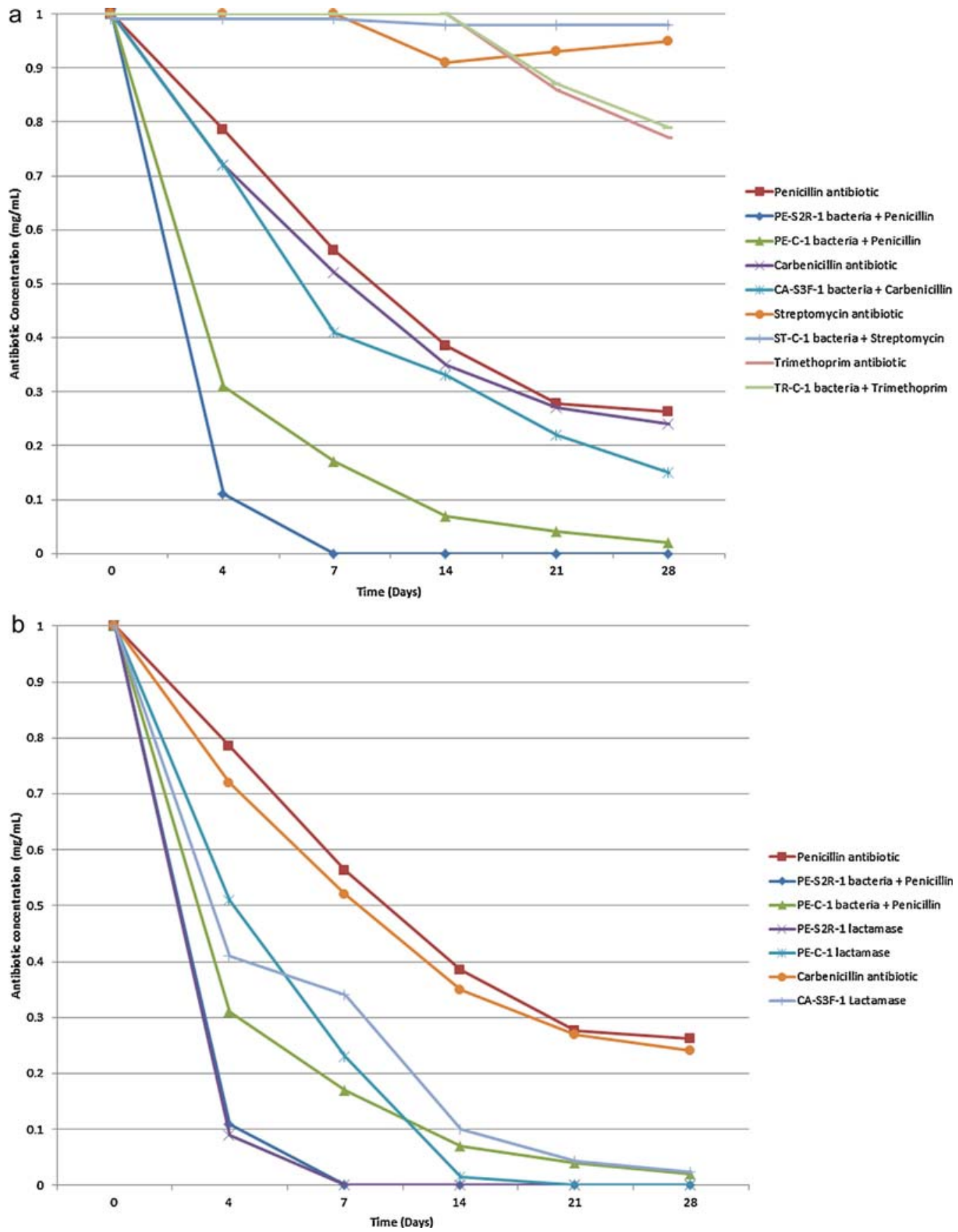

Fig. 4. High-performance liquid chromatography (HPLC) analysis of antibiotic degradation over 28 days in the presence of (a) bacteria and the corresponding antibiotics and (b) $\beta$-lactamases and the corresponding antibiotics in comparison with degradation by the bacteria. PE-S2R-1, Burkholderia sp.; PE-C-1, Pseudomonas sp.; CA-S3F-1, Burkholderia sp.; ST-C-1, Achromobacter sp.; TR-C-1, Pseudomonas sp.

penicillin to almost nothing by Day 4 . The rate of degradation by the extracted $\beta$-lactamase is almost identical to that of the bacteria (PE-S2R-1). The $\beta$-lactamases from CA-S3F-1 and PE-C-1 showed a similar rate of degradation. Therefore, no additional mechanism other than the antibiotic resistance mechanism ( $\beta$-lactamase) was required by any of these bacteria to degrade the $\beta$-lactam antibiotics penicillin and carbenicillin.

As streptomycin and trimethoprim were not degraded after 28 days of incubation with the bacteria, concentrations of the five bacteria used in the HPLC experiments were monitored in SCS medium without antibiotic over 28 days. The hypothesis was that the bacteria may be viable at the end of the 28 days but that they have not grown over the 28 days and thus could survive in a non-growing state. The initial bacterial counts ranged from $1.27 \times 10^{3} \mathrm{CFU} / \mathrm{mL}$ to $1.55 \times 10^{4} \mathrm{CFU} / \mathrm{mL}$ (Fig. 3 ).

\section{Discussion}

Reproducibility and verification of results are vital components of the basis of scientific discovery. We aimed to reproduce and verify the discovery of soil bacteria capable of catabolising antibiotics [3]. Within the 4 years since this hypothesis was reported, the paper describing these results has been cited 145 times (Google Scholar, 28 January 2013). However, the hypothesis has not been verified or reproduced. We propose, based on the results of the current study and a lack of verified results concurring with the 
hypothesis of soil bacteria catabolising antibiotics, that soil bacteria do not catabolise the antibiotics and do not use any novel mechanism of degradation. Using bacteria from the previous study and from this study, we have identified that the $\beta$-lactams were degraded by the well-characterised $\beta$-lactamase resistance mechanism. The soil bacteria do not therefore represent a source of novel antibiotic-degrading enzymes. This study has also identified that bacteria with the catabolising phenotype did not degrade streptomycin or trimethoprim. We propose that no evidence has been shown to indicate that soil bacteria can degrade any other classes of antibiotics. The 'carbon-free' medium (SCS) contained $15 \mathrm{mg} / \mathrm{mL}$ EDTA that, according to Dantas et al., would be sufficient to support bacterial growth [3]. This was overlooked by the seminal study.

Using the same methodologies as previously reported, this study has identified soil bacteria with high-level resistance to 14 different antibiotics from different classes [3]. Bacteria with the same phenotype have previously been described as subsisting on the antibiotics as a sole carbon source [3]. However, the current study has identified that bacteria with a catabolism phenotype did not degrade streptomycin or trimethoprim. Resistance to these antibiotics has to date been restricted to target site mutation, modification, efflux, production of an additional target, or hyperproduction of the target site [19]. High-level resistance in Pseudomonas and Burkholderia spp. has been associated with intrinsic resistance to these antibiotics $[20,21]$. The $\beta$-lactam antibiotics were destroyed in the presence of the soil bacteria, however destruction of the antibiotics was due to the production of $\beta$-lactamases. Production of $\beta$-lactamases was first reported in 1940 [22]. There has been, however, since then no evidence to suggest that production of $\beta$ lactamases is linked to the utilisation and subsistence of bacteria on antibiotics as a sole carbon source.

Using the same methods and some of the bacteria as the previous study describing subsistence on antibiotics as a sole carbon source, we come to a contradictory conclusion. We conclude that the bacteria previously described as using antibiotics as a sole carbon source have either not degraded the antibiotics, and thus cannot utilise whole antibiotics as a carbon source, or have degraded the antibiotics using well-characterised resistance mechanisms, which have not previously been linked to utilisation as a sole carbon source.

\section{Acknowledgments}

This work was conducted within the European research network COST TD0803 Detecting evolutionary hotspots of antibiotic resistances in Europe (DARE). The authors thank A. Baechli, T. Poiger and H.-U. Weilenmann for technical assistance and discussion.

Funding: This project was funded by the Swiss Federal Office for Agriculture, the Swiss Federal Office for the Environment and the Swiss Expert Committee for Biosafety (SECB).

Competing interest: None declared.

Ethical approval: Not required.

\section{References}

[1] Levy SB, Marshall B. Antibacterial resistance worldwide: causes, challenges and responses. Nat Med 2004;10(12 Suppl.):S122-9.

[2] Centers for Disease Control and Prevention (CDC). Emergence of Mycobacterium tuberculosis with extensive resistance to second-line drugs worldwide, 2000-2004. MMWR Morb Mortal Wkly Rep 2006;55: 301-5.

[3] Dantas G, Sommer MO, Oluwasegun RD, Church GM. Bacteria subsisting on antibiotics. Science 2008;320:100-3.

[4] Davies J, Davies D. Origins and evolution of antibiotic resistance. Microbiol Mol Biol Rev 2010;74:417-33.

[5] Anderson IC, Campbell CD, Prosser JI. Diversity of fungi in organic soils under a moorland - Scots pine (Pinus sylvestris L.) gradient. Environ Microbiol 2003;5:1121-32.

[6] Gomes NCM, Fagbola O, Costa R, Rumjanek NG, Buchner A, Mendona-Hagler L, et al. Dynamics of fungal communities in bulk and maize rhizosphere soil in the tropics. Appl Environ Microbiol 2003;69:3758-66.

[7] Milling A, Smalla K, Maidl FX, Schloter M, Munch JC. Effects of transgenic potatoes with an altered starch composition on the diversity of soil and rhizosphere bacteria and fungi. Plant Soil 2004;266:23-39.

[8] Will C, Thürmer A, Wollherr, Nacke H, Herold N, Schrumpf M, et al. Horizonspecific bacterial community composition of German grassland soils, as revealed by pyrosequencing-based analysis of 16S rRNA genes. Appl Environ Microbiol 2010;76:6751-9.

[9] Hammes FA, Egli T. New method for assimilable organic carbon determination using flow-cytometric enumeration and a natural microbial consortium as inoculum. Environ Sci Technol 2005;39:3289-94.

[10] Vital M, Stucki D, Egli T, Hammes F. Evaluating the growth potential of pathogenic bacteria in water. Appl Environ Microbiol 2010;76: 6477-84.

[11] D'Costa VM, McGrann KM, Hughes DW, Wright GD. Sampling the antibiotic resistome. Science 2006;311:374-7.

[12] Clinical and Laboratory Standards Institute. Methods for dilution antimicrobial susceptibility tests for bacteria that grow aerobically; approved standard. 8th ed. Document M7-A8. Wayne, PA: CLSI; 2009.

[13] Housman ST, Sutherland C, Nicolau DP. In vitro evaluation of Rib-X novel compounds' potency against selected isolates of Pseudomonas aeruginosa. In: 51st Interscience Conference on Antimicrobial Agents and Chemotherapy (ICAAC). Washington, DC: ASM Press; 2011.

[14] Ludwig W, Strunk O, Westram R, Richter L, Meier H, Yadhukumar, et al. ARB: a software environment for sequence data. Nucleic Acids Res 2004;32:1363-71.

[15] Clinical and Laboratory Standards Institute. Performance standards for antimicrobial disk susceptibility tests; approved standard. 10th ed. Document M02-A10. Wayne, PA: CLSI; 2009.

[16] Jeon JH, Kim SJ, Lee HS, Cha SS, Lee JH, Yoon SH. Novel metagenome-derived carboxylesterase that hydrolyzes $\beta$-lactam antibiotics. Appl Environ Microbiol 2011;77:7830-6.

[17] Juan C, Maciá MD, Gutiérrez O, Vidal C, Pérez JL, Oliver A. Molecular mechanisms of $\beta$-lactam resistance mediated by AmpC hyperproduction in Pseudomonas aeruginosa clinical strains. Antimicrob Agents Chemother 2005;49: 4733-8.

[18] Livermore DM, Mushtaq S, Ge Y, Warner M. Activity of cephalosporin CXA-101 (FR264205) against Pseudomonas aeruginosa and Burkholderia cepacia group strains and isolates. Int J Antimicrob Agents 2009:34:402-6.

[19] Amyes S, Thomson C, Miles R, Tilotson G. Antimicrobial chemotherapy. London, UK: Martin Dunitz; 1996.

[20] Masuda N, Sakagawa E, Ohya S, Gotoh N, Tsujimoto H, Nishino T. Contribution of the MexX-MexY-OprM efflux system to intrinsic resistance in Pseudomonas aeruginosa. Antimicrob Agents Chemother 2000;44: 2242-6.

[21] Köhler T, Kok M, Michea-Hamzehpour M, Plesiat P, Gotoh N, Nishino T, et al. Multidrug efflux in intrinsic resistance to trimethoprim and sulfamethoxazole in Pseudomonas aeruginosa. Antimicrob Agents Chemother 1996;40: 2288-90.

[22] Abraham E, Chain E. An enzyme from bacteria able to destroy penicillin. Nature 1940;46:837. 